\title{
aPKC drives cilia-independent Hedgehog signaling to maintain basal cell carcinoma growth
}

Tuyen T. L. Nguyen ${ }^{1}$, Ung Seop Jeon ${ }^{1}$, Vama Jhumkhawala ${ }^{1}$, Kevin C. Tan ${ }^{1}$, Vinay Kumar ${ }^{3}$, Whitney E. England ${ }^{3}$, Linda T. Doan ${ }^{2}$, Robert C. Spitale ${ }^{3}$, Scott X. Atwood ${ }^{1,2,4}$

${ }^{1}$ Department of Developmental and Cell Biology, University of California, Irvine, Irvine, CA 92697, USA

${ }^{2}$ Department of Dermatology, University of California, Irvine, Irvine, CA 92697, USA

${ }^{3}$ Department of Pharmaceutical Sciences, University of California, Irvine, Irvine, CA 92697, USA

${ }^{4}$ Chao Family Comprehensive Cancer Center, University of California, Irvine, Irvine, CA, 92697, USA

Corresponding author:

Scott X. Atwood (satwood@uci.edu) 


\begin{abstract}
Primary cilia loss is a common feature of advanced cancers. While primary cilia are necessary to initiate Hedgehog $(\mathrm{HH})$-driven cancers, how $\mathrm{HH}$ pathway activity is maintained in advanced cancers devoid of primary cilia is unclear. Here, we find that $\mathrm{HH}$-driven basal cell carcinoma (BCC) accumulate mutations in the Alström and Usher syndrome genes in advanced and SMO inhibitorresistant tumors. Loss of Alström and Usher syndrome gene expression, which are common underlying causes of deafness and blindness, suppresses ciliogenesis and $\mathrm{HH}$ signaling. Atypical protein kinase $\mathrm{C}$ iota/lambda (aPKC) is a GLI1 kinase with higher expression in advanced BCCs and we show that a constitutively active isoform drives $\mathrm{HH}$ pathway activity and mutually antagonizes primary cilia. Overexpression of the constitutively active aPKC variant can maintain $\mathrm{HH}$ pathway activity in the absence of primary cilia and can drive resistance to the SMO antagonist vismodegib regardless of cilia status. Finally, superficial BCCs display less primary cilia and higher $\mathrm{APKC}$ expression, which is inversely correlated in nodular BCC subtypes. Our results suggest aPKC may serve as a biomarker for SMO inhibitor sensitivity and a target for clinical application.
\end{abstract}

\title{
Introduction
}

The primary cilium is a non-motile, centrosome-based, microtubule signaling and sensing organelle that emanates from most mammalian cells after exit from mitosis (Satir et al., 2010). Primary cilia house proteins that transduce many signals, including the Hedgehog $(\mathrm{HH})$ pathway, which are required during development and homeostasis. Alterations in the signaling or structural components have been implicated in multiple ciliopathies and cancer (Hildebrandt et al., 2011), such as basal cell carcinoma (BCC). $\mathrm{BCC}$ s require high sustained $\mathrm{HH}$ signaling for growth but paradoxically lose primary cilia during later stages while maintaining $\mathrm{HH}$ pathway activation (Atwood et al., 2015; Kuonen et al., 2019). Loss of primary cilia also occurs in advanced or metastatic breast cancer (Yuan et al., 2010), renal cancer (Schraml et al., 2009), prostate cancer (Hassounah et al., 2013), pancreatic cancer (Seeley et al., 2009), and melanoma (Kim et al., 2011), indicating a wide-spread issue in late-stage cancers that are not well understood.

In vertebrates, the $\mathrm{HH}$ signaling pathway is essential for embryonic development (Varjosalo and Taipale, 2008) and regulates proliferation, migration, angiogenesis, and stem cell regeneration in adult tissues (Zheng et al., 2010). Vertebrate HH signals through the primary cilium by shutting down the cholesterol transporter PTCH1, allowing activation of the G-protein coupled receptor SMO and the transcription factor GLI2, which transcribes $\mathrm{HH}$ target genes including the signal 
amplifier GLI1 (Zhang et al., 2018). Inappropriate HH pathway activation drives BCC initiation and progression, mostly through mutations that inhibit PTCH1 $(\sim 70 \%)$ or activate SMO ( 20\%) (Bonilla et al., 2016). Loss of primary cilia typically leads to attenuation of $\mathrm{HH}$ signaling (Fu et al., 2014; Wong et al., 2009), however concomitant activation of GLI2 can accelerate BCC tumorigenesis (Fu et al., 2014; Han et al., 2009) in a process not well understood.

BCCs are locally invasive epithelial tumors that affect approximately 4 million people in the United States annually (Nguyen et al., 2019) Most small early-stage tumors can be surgically removed. However, advanced or metastatic BCCs require alternative treatments such as SMO antagonists that shut down the HH pathway (Atwood et al., 2015). At present, most advanced BCC patients either acquire or are innately resistant to SMO antagonists. In fact, the most frequently prescribed SMO antagonist, vismodegib, is inherently ineffective in $57 \%$ of advanced BCC cases (Sekulic et al., 2012) and $21 \%$ of patients with initial tumor regression acquire resistance after 56 weeks of treatment (Chang and Oro, 2012). Roughly half of drug-resistant BCC patients harbor SMO mutations that either block drug binding or render SMO constitutively active (Atwood et al., 2015; Sharpe et al., 2015), indicating a dire need to identify downstream therapeutic targets to combat resistance to SMO antagonists. Recently, we observed an increase in mutations within ciliaassociated genes that resulted in disrupted primary cilia and allowed BCCs to convert to squamous cell carcinomas (SCCs) in a small percentage of tumors by shutting down the $\mathrm{HH}$ pathway and increasing the RAS/MAPK pathway to confer resistance to SMO antagonists (Kuonen et al., 2019). These converted SCCs are sensitive to MAPK inhibitors but represent a small percentage of the total resistant BCCs which largely maintain $\mathrm{HH}$ pathway activation (Atwood et al. 2015).

Atypical Protein Kinase C lambda/iota (aPKC) has been shown to activate HH signaling in BCC and non-small cell lung cancer (Atwood et al., 2013; Yuan et al. 2007), suggesting aPKC's potential as an alternative therapeutic target to SMO in HH-driven cancers. Developmentally, aPKC plays a central role in determining cell polarity (Roignot et al. 2013) and can function as an oncogenic kinase where it phosphorylates the zinc finger domain of GLI1 to activate DNA binding and transcriptional activity (Atwood et al., 2013). Interestingly, PRKCI is also a GLI1 target gene that is highly expressed in human BCCs, with significantly higher expression in vismodegibresistant tumors (Atwood et al., 2013). Inhibition of aPKC using a peptide inhibitor shuts down $\mathrm{HH}$ signaling and tumor growth in a murine model of BCC (Atwood et al., 2013) and can slow the 
growth of BCC cells that harbor vismodegib-resistant SMO mutations (Atwood et al., 2015), suggesting aPKC can be a viable therapeutic target in these contexts.

In this study, we find that loss of highly mutated cilia-associated genes disrupts primary cilia and attenuates $\mathrm{HH}$ pathway activation. Loss of primary cilia results in higher aPKC expression, which normally serves to restrict ciliogenesis (Drummond et al. 2018). Expression of an aPKC isoform that only contains the kinase domain promotes $\mathrm{HH}$ signaling in the presence or absence of primary cilia and can confer resistance to vismodegib. Finally, superficial BCC tumors show a decrease in primary cilia and concomitant increase in aPKC expression, which is inversely correlated to nodular BCC subtype, suggesting aPKC may serve as a biomarker for SMO inhibitor sensitivity and a target for combination therapies.

\section{Results}

Disruption of Alström and Usher syndrome genes suppress primary cilia and HH signaling We previously reported that the 303 cilia-specific genes that comprise the SYSCILIA list (van Dam et al. 2013) had significantly lower mutation rates in human BCCs compared to genome-wide mutation rates (Bonilla et al. 2016; Kuonen et al. 2019), an expected result given the importance of the $\mathrm{HH}$ pathway for BCC initiation and progression. However, many SMO antagonist-resistant tumors displayed clonal loss of primary cilia (Kuonen et al. 2019), suggesting that some of the cilia-specific genes may be mutated more than normal. When we analyzed 161 cilia-specific genes that contained at least one mutation in our previously identified list of genes commonly mutated in SMO antagonist-resistant human BCCs (Atwood et al. 2015), we found a subset of highly mutated genes in drug-resistant BCCs compared to drug-sensitive and normal aged skin

(Figure 1A, Supplementary Table 1). PTCH1, a negative suppressor of the $\mathrm{HH}$ pathway that is mutated in $\sim 70 \%$ of human BCC (Bonilla et al. 2016), is highly mutated as expected. ALMS1, which encodes a centrosomal protein mutated in Alström syndrome (Hearn 2019), is the most highly mutated gene in SMO antagonist-resistant BCC. Interestingly, four Usher syndromerelated genes, which are a major cause of deaf-blindness in humans (Géléoc and El-Amraoui, 2020), are overrepresented in the top 11 most mutated genes. Not known to cause defects in primary cilia or $\mathrm{HH}$ signaling, Usher Type 1 proteins (CDH23, MYO7A, PCDH15, USH1C, and USH1G) connect the apical tips of hair bundle stereocilia to each other whereas Usher Type 2 proteins (GPR98, PDZD7, USH2A, and WHRN) connect the basal portion of these stereocilia. To determine differences in mutation rate of Usher syndrome genes to the rest of the genome, we utilized both Gorlin syndrome patient samples (Chiang et al. 2018, National Institutes of Health 
Sequence Read Archive SAMN07507265-SAMN07507288) and our SMO antagonist-resistant human BCCs. When we compare Usher Type 1 and 2 genes in the cancer datasets to the rest of the human exome, we observe significant increases in mutation rate from Gorlin, drug-sensitive, and drug-resistant BCCs, whereas normal aged skin or patient-matched blood samples do not change or decrease, respectively (Figure 1B). These data suggest that highly mutated ciliopathyassociated genes from Alström and Usher syndromes may be the underlying cause of primary cilia loss in advanced and drug-resistant BCC.

Despite clonal loss of primary cilia in many advanced and drug-resistant human BCC, the vast majority of tumors maintained HH target gene induction (Atwood et al. 2015; Kuonen et al. 2019; Sharpe et al. 2015). To explore the possibility that disrupting expression of Alms1 and Usher genes positively influences primary ciliogenesis and $\mathrm{HH}$ signaling, we used shRNA to knock down (KD) expression of each gene in HH-responsive NIH3T3 murine fibroblasts. We used Kif3a KD as a positive control as KIF3A is known to be required for primary ciliogenesis and $\mathrm{HH}$ signaling (Huangfu et al., 2003; Marszalek et al., 1999; Takeda et al., 1999). As expected, Kif3a KD resulted in loss of primary cilia, a reduction in axoneme length, and suppressed $\mathrm{HH}$ signaling compared to a scramble shRNA control (Figures 1C-F, Supplementary Figure 1A). Alms1 KD phenocopied Kif3a KD, despite normal primary ciliogenesis in Alms $1^{-/}$mice that present similar features as patients with Alström syndrome (Collin et al. 2005) and in primary human fibroblasts cultured from Alström syndrome patients (Chen et al. 2017). Despite not previously linked to primary cilia or HH signaling, KD of Usher Type 1 genes Cdh23 and Pcdh15 or Usher Type 2 genes Gpr98 and Ush2a also resulted in ciliary loss, reduced axoneme length, and diminished $\mathrm{HH}$ signaling compared to scrambled shRNA control (Figures 1C-F, Supplementary Figure 1A). To rule out a cell-type specific role in primary ciliogenesis and $\mathrm{HH}$ signaling for each of these genes, the same shRNA-mediated KD of gene expression was applied to ASZ001 murine BCC cells and resulted in comparable reductions (Figures 1G-J, Supplementary Figure 1B). These results suggest that disruption of genes associated with Alström and Usher syndromes may underlie the primary cilia defects seen in advanced and drug-resistant BCC, but they alone do not allow the maintenance of $\mathrm{HH}$ signaling in these tumors.

\section{Constitutively active aPKC isoform promotes $\mathrm{HH}$ signaling}

To explore the idea that a second event is necessary to maintain $\mathrm{HH}$ signaling in the absence of primary cilia, we narrowed our focus to the GLI transcription factors. Previous work indicated that primary cilia loss combined with activated GLI2, but not activated SMO, accelerated BCC (Wong 
et al. 2009) and medulloblastoma (Han et al. 2009) tumor growth. As GLI1/GLI2 somatic copy number alterations are only seen in $8 \%$ of human BCCs and would not apply to most advanced and drug-resistant tumors (Bonilla et al. 2016), we instead explored whether aPKC overexpression could promote $\mathrm{HH}$ signaling. We previously reported that aPKC phosphorylates and activates GLI1 and is required for $\mathrm{HH}$ signaling and BCC tumor growth in a primary ciliaindependent manner (Atwood et al. 2013). Most importantly, aPKC was significantly overexpressed in a majority of sporadic and SMO antagonist-resistant human BCCs, although its role in promoting $\mathrm{HH}$ signaling was not tested. To examine the role of aPKC overexpression on $\mathrm{HH}$ pathway activation, we overexpressed the full-length wild-type isoform of aPKC (aPKC-FL) or the kinase dead variant (aPKC-KD) in NIH3T3 cells but did not observe changes in $\mathrm{HH}$ signaling as measured by Gli1 mRNA levels in the presence of Shh-CM (Figure 2A). Interestingly, the constitutively active isoform of aPKC where the regulatory amino-terminal domain is truncated (aPKC-K; amino acids 235-587), significantly increased HH signaling (Figure 2A). The aPKC-K isoform, otherwise known as PKM, plays an important role in long-term memory potentiation (Tsokas et al. 2016). To determine whether this isoform is present outside of brain tissue, we performed western blots of a variety of cell types and observed both aPKC-FL and aPKC-K isoform expression in primary human keratinocytes, human embryonic kidney 293T cells, mouse NIH3T3 fibroblasts, and mouse ASZ001 BCC cells using an antibody that recognizes the kinase domain of aPKC (Figure 2C). We also observed both aPKC-FL and aPKC-K isoform expression in western blots of the normal human breast epithelial cell line MCF10 and multiple human breast cancer cell lines (Figure 2D). In addition, when we quantify reads per exon within the PRKCI gene from our previously published RNA-seq datasets of advanced human BCCs (Atwood et al. 2015), we observed more reads within exons 9-18 (corresponding to aPKC-K) than within exons 1-8 (corresponding to the regulatory region) (Figure 2E-F), suggesting that the aPKC-K isoform is present in multiple normal and diseased cell types and advanced BCCs.

To verify that aPKC is highly active in human BCCs, we took a bioinformatics approach and inferred an aPKC-specific gene signature list from our previously published RNA-seq analysis of BCC cells treated with aPKC or SMO antagonists (Atwood et al., 2013). The vast majority of differentially expressed transcripts are common between the two inhibitors, with $5 \%$ of transcripts unique to aPKC antagonist and 10\% unique to SMO antagonist (Supplementary Table 2). We compared each gene list to our previously published RNA-seq datasets of 14 tumor-normal pairs of advanced BCCs (Atwood et al. 2015) and found 34 aPKC-specific, 76 SMO-specific, and 736 commonly shared transcripts that were differentially expressed by two-fold or more (Figure 2G, 
Supplementary Table 2). Two-thirds of each gene list showed significant increases in gene expression compared to the matched normal sample. Upregulated genes in the aPKC-specific response correspond to cell cycle, cancer-related pathways, and the ciliary landscape according to WikiPathways analysis (Slenter et al. 2018) (Figure 2H, Supplementary Table 3). Notable genes include the MCM genes and their downstream target UBEC2, which are involved in the transcriptional control of ciliogenesis and centrosome amplification (Casar Tena et al. 2019).

\section{aPKC and primary cilia mutually inhibit each other}

We previously reported that loss of aPKC increased ciliogenesis and axoneme length, while suppressing HH pathway activation (Atwood et al. 2013; Drummond et al. 2018), suggesting that aPKC expression may dynamically regulate ciliogenesis. To further define the association between ciliogenesis and aPKC expression, we examined primary cilia upon aPKC overexpression. Overexpression of either aPKC-FL or aPKC-K significantly reduces primary cilia in NIH3T3 cells (Figure 3A-B), suggesting that $\mathrm{HH}$ pathway modulation is not necessary for aPKC's cilia-mediated effects. On the other hand, when primary cilia are disrupted by Kif3a-, Gpr98-, or Cdh23-mediated KD, aPKC protein expression is significantly increased (Figure 3CD). Furthermore, these effects also occur in vivo as immunofluorescence analysis of allografted murine BCC tumors generated from Ptch1 ${ }^{+/}$; Trp53 $3^{\text {flox/lox. }}$ Krt14-Cre-ER2 mice (Atwood et al. 2013; Wang et al., 2011) treated with DMSO control or the aPKC-specific inhibitor PSI showed a significant increase in the number of ciliated cells and axoneme length in PSI-treated samples

(Figure 3E-G). Moreover, close examination of each tumor sample regardless of treatment revealed differential aPKC expression within each sample, with higher aPKC expression coinciding with lower ciliation and lower expression coinciding with higher ciliation (Figure $\mathbf{3 H}$ I). Altogether, these results indicate that aPKC and primary cilia mutually inhibit each other and suggest that the increase in aPKC expression in advanced and drug-resistant human BCCs may contribute to cilia loss.

\section{aPKC activity maintains $\mathrm{HH}$ signaling and promotes drug resistance with or without primary cilia}

To characterize the role of aPKC and primary cilia in resistance to SMO antagonists, we treated NIH3T3 and ASZ001 cells stably expressing aPKC-K or a vector control with the SMO antagonist vismodegib. Control cells showed a significant reduction in Gli1 mRNA levels upon treatment with vismodegib as expected (Figure 4A-B). On the other hand, aPKC-K expression showed a significant increase in $\mathrm{HH}$ target gene induction compared to vector control and was able to 
maintain Gli1 mRNA levels when treated with vismodegib at levels significantly above control cells treated with DMSO (Figure 4A-B), suggesting that aPKC activity can partially promote drug resistance.

We next examined how disruption of primary cilia influenced vismodegib response. shRNAmediated KD of Kif3a, Cdh23, and Gpr98 all showed a reduction in Gli1 mRNA levels that was unaffected by vismodegib treatment (Figure 4C). aPKC-K expression in KD cells significantly elevated $\mathrm{HH}$ target gene induction above control cells treated with DMSO and addition of vismodegib did not further reduce Gli1 mRNA levels (Figure 4C). These results suggest that high aPKC activity can maintain $\mathrm{HH}$ pathway activity in advanced and drug-resistant human BCCs experiencing clonal loss of primary cilia either through aPKC activity itself or through accumulation of mutations that disrupt primary ciliogenesis.

\section{Human primary BCC tumors display differential ciliation, aPKC expression, and HH signaling}

Recent work indicates that residual mouse BCC tumors that regrow after cessation of vismodegib treatment transition from a drug-sensitive hair follicle gene expression signature to a drugresistant interfollicular epidermal signature (Biehs et al. 2018; Sanchez-Danes et al. 2018). To explore whether aPKC and primary cilia may be participating in this type of resistance, we quantified primary cilia and aPKC expression in nodular and superficial human BCC subtypes. Nodular BCCs are thought to arise from hair follicles (Grachtchouk et al. 2011); whereas superficial BCCs arise from the interfollicular epidermis (Tan et al. 2018). Our results showed significantly higher primary ciliogenesis in nodular BCCs compared to superficial tumors (Figure 4D-E). At the same time, the average expression of total aPKC and activated aPKC (phosphorylated at T410) proteins were significantly lower in nodular BCCs than in superficial tumors (Figure 4F-H). Similarly, total GLI1 and activated GLI1 (phosphorylated at T304 by aPKC) were also significantly reduced in nodular BCCs (Figure 4F, I-J). These results suggest that superficial BCCs may be more resistant to SMO antagonist therapy and that aPKC activity combined with loss of primary cilia may contribute to an interfollicular epithelial state that promotes BCC drug resistance.

\section{DISCUSSION}

The vertebrate $\mathrm{HH}$ signaling pathway is the driving force in $\mathrm{BCC}$ formation and maintenance (Epstein, 2008; Pak and Segal, 2016; Wu et al., 2017), which is heavily dependent on intact 
primary cilia (Bangs and Anderson, 2017). Yet, HH signaling remains elevated in advanced BCCs where primary cilia are significantly reduced. Here, we show that disruption of Alström syndrome (ALMS1) and Usher syndrome (CDH23, PCDH15, GPR98, USH2A) genes suppress primary ciliogenesis and inhibit $\mathrm{HH}$ signaling (Figure 1C-J). How these genes regulate primary ciliogenesis and $\mathrm{HH}$ signaling are unclear. ALMS1 has been identified through AP-MS studies as a possible binding partner of GPRASP2, a GPCR-associated sorting protein that has been implicated in SMO ciliary translocation (Jung et al., 2016). PCDH15 localization to kinocilia is dependent on FGFR1 activity (Honda et al., 2018), an interesting connection given that FGFR regulates GLI1 expression downstream of SMO in medulloblastomas (Neve et al., 2019). In addition, USH2A and PCDH15 can both bind directly to GBX2 (Roelseler et al., 2012), a HHresponsive protein in thalamic differentiation (Szabó et al., 2009). Moreover, CDH23 is a Dachsous-like protein that may regulate $\mathrm{HH}$ signaling given that Dally and Dally-like, the downstream targets of tumor suppressor Dachsous, have been shown to modulate the $\mathrm{HH}$ signaling pathway in Drosophila (Williams et al., 2010).

Ciliogenesis is essential to maintain cellular homeostasis, specifically to facilitate proper signaling of the HH, WNT, NOTCH, Hippo, PDGFRa, FGF, and other GPCR pathways in certain contexts (Wheway et al., 2018). Many of these pathways facilitate tumor growth. So primary cilia loss in advanced tumors is unexpected from a mechanistic view. Disruption of primary cilia have been observed in many advanced cancers, including cancers of the brain (Han et al., 2009), breast (Menzl et al., 2014), kidney (Schraml et al., 2009), skin (Zingg et al., 2018), pancreas (Seeley et al., 2009), thyroid (Lee et al., 2018; Menzl et al., 2014), ovary (Egeberg et al., 2012), and prostate (Hassounah et al., 2013). How primary cilia loss benefits tumor growth is unclear. Primary cilia disruption can facilitate the conversion from basal to squamous cell carcinoma in a small subset of cases by shutting down the $\mathrm{HH}$ pathway and concomitantly increasing the RAS/MAPK pathway, conferring resistance to SMO antagonists (Kuonen et al., 2019). Besides switching tumor identity, generating primary cilia during the $\mathrm{G} 1$ portion of the cell cycle may be energetically expensive and disruption of this process may allow for faster cycling of tumor cells to offset the loss of the cilia-mediated driving oncogenic signal (Liu et al. 2018).

aPKC has been established as an oncogene in many cancer models including ovarian (Eder et al., 2005), lung (Regala et al., 2005), brain (Baldwin et al., 2008), esophagus (Yang et al., 2008), breast (Kojima et al., 2008), and pancreatic (Evans et al., 2003) cancers, where it is often tied to its cell polarity functions. Here we show that the constitutively active aPKC isoform (aPKC-K), but 
not full-length aPKC (aPKC-FL), drives $\mathrm{HH}$ target gene induction and may serve as an oncogene in BCC. Our data are consistent with previous findings that aPKC-K overexpression, but not aPKC-FL, leads to formation of large neuroblast tumors in Drosophila larval brains (Lee et al. 2006). aPKC-K does not polarize like its full-length counterpart in neuroblasts, suggesting that aPKC-K's role in $\mathrm{HH}$ target gene induction may be independent from polarity. The aPKC-K isoform is also required for mouse brain development (Hirai et al., 2003) and long-term memory potentiation (Tsokas et al. 2016), indicating critical roles for this isoform in the brain. Whether aPKC-K is functionally expressed outside of the brain is less clear. We demonstrate aPKC-K expression in mammalian keratinocytes, embryonic kidney cells, normal and cancerous breast cells, fibroblasts, and BCC cells, suggesting that aPKC-K may also have essential roles in these tissues.

Recent work showing residual mouse BCC tumors can regrow after cessation of vismodegib treatment indicate these tumors transition from a drug-sensitive hair follicle gene expression signature to a drug-resistant interfollicular epidermal signature (Biehs et al. 2018; Sanchez-Danes et al. 2018). How an interfollicular epidermal signature promotes drug resistance is not clear. Our data pointing to a mutual inhibition between aPKC expression and primary ciliogenesis may provide some insight. We show that nodular BCC tumors, which predominantly form from hair follicles, express less aPKC and generate more primary cilia; whereas superficial tumors that derive from the interfollicular epidermis express significantly more aPKC and produce less primary cilia. This mutual antagonism may provide more cilia-localized SMO in drug-sensitive tumors for vismodegib to act upon and less aPKC to maintain $\mathrm{HH}$ signaling in presence of drug, with the reverse mechanism occurring in drug-resistant tumors. These data suggest aPKC may serve as a biomarker for SMO inhibitor sensitivity in clinical samples and may be a useful target for future clinical development.

\section{MATERIALS AND METHODS}

\section{Ethics statements}

Human clinical studies were approved by the Ethics Committee of the University of California, Irvine. All human studies were performed in strict adherence to the Institutional Review Board (IRB) guidelines of the University of California, Irvine (2009-7083).

\section{Human samples}


Written informed consent was obtained for all archived human samples and was reviewed by the University of California Irvine IRB. Human normal epidermis and BCC samples were collected from UC Irvine Medical Center. Paraffinized samples were sectioned with a rotary microtome (Leica RM2155) at $7 \mu \mathrm{m}$ for analysis. Samples were deparaffinized as described by Abcam and antigen retrieval was performed using a Tris-EDTA buffer (10 nM Tris base, $1 \mathrm{mM}$ EDTA, 0.05\% Tween $20, \mathrm{pH} 9.0$ ) at $100^{\circ} \mathrm{C}$ for $10 \mathrm{~min}$.

\section{RNA Sequencing Analysis}

RNA-seq data were obtained from patient-matched advanced human BCC patients (Atwood et al. 2015). RNA-Seq data were aligned as previously described (Atwood et al. 2015). The NCBI Reference Sequence (RefSeq) databases were used as reference annotations to calculate values of reads per kilobase of transcript per million mapped reads for known transcripts (RPKM). RPKM values were then log2-transformed and heat map analysis was used to visualize the differential gene expression. Pathway enrichment terms from RNA-seq data were obtained using Enrichr (Kuleshov et al. 2016).

\section{Cell culture, drug treatments, and quantitative RT-PCR}

ASZ001 cells (So et al., 2006) were grown in 154CF/PRF media kit (Life Technologies, M154CFPRF500) supplemented with 1\% Penicillin/Streptomycin (Life Technologies, 15140122), 2\% FBS (Life Technologies, 10437028) chelated overnight with Chelex® 100 Resin (Bio-Rad, 1422822), and $0.07 \mathrm{mM} \mathrm{CaCl2}$. NIH3T3 cells (ATCC, CRL 1658) were grown in DMEM media containing 10\% FBS and 1\% Penicillin/Streptomycin. MCF10A cells were grown in DMEM/F12 supplemented with $20 \%$ horse serum, EGF (20 ng/ml), hydrocortisone $(0.5 \mathrm{mg} / \mathrm{ml})$, cholera toxin (100 $\mathrm{ng} / \mathrm{ml})$ and insulin $(10 \mu \mathrm{g} / \mathrm{ml})$. MDA-MB-231, MDA-MB-468 and MCF7 cells were grown in DMEM with $10 \% \mathrm{FBS}$, insulin $(10 \mu \mathrm{g} / \mathrm{ml})$, and $1 \mathrm{mM}$ sodium pyruvate. MCF7 cells were additionally supplemented with 2mM L-Glutamine. T47D cells and HCC1569 cells were grown in RPMI supplemented with $10 \%$ FBS and insulin $(10 \mu \mathrm{g} / \mathrm{ml})$.

At confluence, cells were serum-starved +/- Shh-N ligand (1:100) with or without DMSO (BP2311, Fish Scientific) or 100nM vismodegib (501100852; Fisher Scientific) for 24 hours. RNA was harvested with the Direct-zol RNA MiniPrep Plus kit (ZYMO Research, R2072). Quantitative RTPCR was performed using the iTaq Universal SYBR Green 1-Step Kit (Bio-Rad, 1725151) on a StepOnePlus Real-time PCR system (Applied BioSystem) using primers for Gli1 (forward: 5'GCAGGTG TGAGGCC AGGTAG TGACGA TG-3', reverse: 5'-CGCGGG CAGCAC TGAGGA 
CTTGTC-3'), Gapdh (forward: 5'-AATGAA TACGGC TACAGC AACAGG GTG-3', reverse: 5'AATTGT GAGGGA GATGCT CAGTGT TGGG-3'), mApple (forward: 5'-ACCTAC AAGGCC AAGAAG CC-3', reverse: 5'-GCGTTC GTACTG TTCCAC GA-3'), Kif3a (forward: 5'-CAGACT GGGACA GGCAAG AC-3', reverse: 5'-TTTCTT TTTACC TGCTTG GTCCCT-3'), Alms1 (forward: 5'-TGTGCA GGAGTC TCATGG TT-3', reverse: 5'-TCTCCC CAGGAG ATGATT GGT3'), Cdh23 (forward: 5'-ACTGGC TCACAG AGGAGA GT-3', reverse: 5'-CAGAAG AGGCTT GCCCTG G-3'), Grp98 (forward: 5'-AATAGT CTGCAG GGACTT TATGTT T-3', reverse: 5'CAGCTG GAGGTA TTCCGC TC-3'), Pcdh23 (forward: 5'-TCTTGG CACAGG GACCTA CT-3', reverse: 5'-CGTATT GCCAGT CATCGT CA-3'), Ush2a (forward: 5'-AACCCA TGTGGG ATTAGC CG-3', reverse: 5'-GAGGTG GGTGTC GGTAAA GG-3'), and Prkci (forward: 5'AAGGAA CGATTG GGTTGT CACCCT-3', reverse: 5'-AAGGGT GGAACC ACCTGC TTTTGC T-3'). Fold change in mRNA expression of target genes was measured using $\Delta \triangle \mathrm{Ct}$ analysis with Gapdh as an internal control gene. Experiments were repeated at least three times and data represented as the mean of triplicates \pm SEM.

\section{Generation of stable cell lines}

piggyBac $^{T M}$ transposons containing sequences for full-length wildtype PRKCI (aPKC-FL), fulllength K274W PRKCI (kinase dead, aPKC-KD), or PRKCI 235-587 (constitutively active, aPKCK) were co-transfected with piggyBac ${ }^{\mathrm{TM}}$ transposase using Lipofectamine ${ }^{\circledR} 3000$ reagent (L3000150, LifeTechnologies) per manufacturer's protocols. Transfected cells were selected in $500 \mu \mathrm{g} / \mathrm{mL}$ Geneticin G-418 (50841720, Fisher Scientific) for 1 additional passage after all nontransfected control cells died. Stable cells were then maintained in regular culture media for at least 3 additional passages prior to experiments.

\section{Lentiviral knockdown}

Lentiviral pLKO.1 vector (Open Biosystems) containing shRNAs to Prkci (5'-CCAGAC AGAAAG CAGGTT GTT-3'; Atwood et al., 2013), Kif3a (5'-TCCGCC AGTTTC AGAAAG AAA-3'); or pGIPZ ires GFP vector containing shRNAs to Alms1 (5'-TAGAAG TTAGTT TGTCCTG GC-3'), Cdh23 (5'-ATTGAT GACGAT CTTCAC GCG-3'), Grp98 (5'-TATAAA GTCTAT CATTGG TGG-3'), Pcdh15 (5'-AATAGg GTTCAG TTCTTC CGG-3'), and Ush2a (5'-TTGATG ATAATG TGTCGC G-3') were used. Lentiviral infection was performed on ASZ001 and NIH3T3 cells and assayed between 4 and 6 days depending on the efficiency of knockdown, as determined by mRNA levels using RT-qPCR. 


\section{Immunofluorescence}

Control, transfected, or virally infected cells were seeded in respective growth media. At confluence, the cells were serum starved for 24 hours, then fixed with $4 \%$ paraformaldehyde for 15 minutes, and blocked in PBS containing 1\% normal horse serum and $0.1 \%$ Triton X-100 for 30 minutes. The following antibodies were used: rabbit anti-y-tubulin (1:1000, SAB4503045; Sigma), mouse anti-ARL13B (1:1000, 75-287; Antibodies Inc.), rabbit anti-RFP (1:1000, RL600-401-379; Rockland), rabbit anti-aPKC (1:500, sc-216; Santa Cruz Biotechnology), rabbit anti-p-aPKC T410 (1:500, sc-12894; Santa Cruz Biotechnology), rabbit anti-GLI1 (1:500, AF3455; R\&D Systems), and rabbit anti-P-T304 GLI1 (1:200) (Drummond et al. 2018). Secondary antibodies included Alexa Fluor 488, 546, and 647 (Jackson ImmunoResearch). Slides were mounted in Prolong Diamond Antifade Mountant with DAPI (P36962, Molecular Probes). Confocal images were acquired at room temperature on a Zeiss LSM700 laser scanning microscope with PlanApochromat 40x and 63× oil immersion objectives. Fluorescent images were acquired at room temperature on an EVOS FL Color Imaging System with Plan Fluorite 40x objective. Images were arranged with ImageJ, Affinity Photo, and Affinity Designer.

\section{Western blotting}

Cells or tissues were lysed with 2× SDS sample buffer (100 mM Tris $\mathrm{HCl}$ 6.8, 200 nM DTT, 4\% SDS, $0.2 \%$ bromophenol blue, and $20 \%$ glycerol) and boiled at $95^{\circ} \mathrm{C}$ for 15 minutes. Samples were resolved on a 4-12\% polyacrylamide gradient gel and transferred to nitrocellulose membrane by a wet transfer apparatus. Membranes were blocked with 5\% milk in TBS with $0.05 \%$ Tween-20 before addition of antibodies: rabbit anti-aPKC (1:1000, sc-216; Santa Cruz Biotechnology), mouse anti-ß-Tubulin (1:5000, E7;DSHB), rabbit anti-RFP (1:1000, RL600-401379; Rockland), and Alexa Fluor secondary antibodies. Membranes were imaged and quantified using the LI-COR Odyssey CLx imaging system with built-in Image Studio software.

\section{Statistics}

Statistical analyses were done in GraphPad Prism using two-tailed $t$ tests.

\section{ACKNOWLEDGEMENTS}

We wish to thank Dr. Mike Drummond for his assistance with troubleshooting in the design of aPKC constructs, Dr. Vaishali Jayashankar for provision of breast epithelial and cancer cell lines, as well as all members of the Atwood lab for their constant support. 
This work is funded by NIH grant R01CA237563 (SXA), ACS Research Scholar Award RSG-19089-01-DDC (SXA), NSF-GRFP (TTLN), and a GAANN Fellowship (TTLN). The authors wish to acknowledge the support of the Chao Family Comprehensive Cancer Center Optical Biology Core Shared Resource, supported by the National Cancer Institute of the NIH under award number P30CA062203. The content is solely the responsibility of the authors and does not necessarily represent the official views of the $\mathrm{NIH}$.

\section{CONTRIBUTIONS}

S.X.A. and T.T.L.N. conceived the project; S.X.A. supervised research; T.T.L.N. performed experiments; T.T.L.N., U.S.J., V.J., K.C.T., and S.X.A. quantified experimental data; V.K., W.E.E., and R.C.S. analyzed RNA-seq data; L.T.D. collected and annotated human clinical samples; S.X.A. and T.T.L.N. wrote the manuscript. All authors analyzed and discussed the results and commented on the manuscript.

\section{REFERENCES}

Atwood, S.X., M. Li, A. Lee, J.Y. Tang, and A.E. Oro. (2013). GLI activation by atypical protein kinase C $\mathrm{I} / \lambda$ regulates the growth of basal cell carcinomas. Nature. 494:484-488. https://doi.org/10.1038/nature11889

Atwood, S. X., Sarin, K. Y., Whitson, R. J., Li, J. R., Kim, G., Rezaee, M., Ally, M. S., Kim, J., Yao, C., Chang, A. L., Oro, A. E., \& Tang, J. Y. (2015). Smoothened variants explain the majority of drug resistance in basal cell carcinoma. Cancer cell, 27(3), 342-353. https://doi.org/10.1016/j.ccell.2015.02.002

Baldwin, R. M., Parolin, D. A., \& Lorimer, I. A. (2008). Regulation of glioblastoma cell invasion by PKC iota and RhoB. Oncogene, 27(25), 3587-3595. https://doi.org/10.1038/sj.onc.1211027 Bangs, F., \& Anderson, K. V. (2017). Primary Cilia and Mammalian Hedgehog Signaling. Cold $\begin{array}{llll}\text { Spring Harbor perspectives in biology, } 9(5), & \text { a028175. }\end{array}$ https://doi.org/10.1101/cshperspect.a028175

Bonilla, X., Parmentier, L., King, B., Bezrukov, F., Kaya, G., Zoete, V., Seplyarskiy, V. B., Sharpe, H. J., McKee, T., Letourneau, A., Ribaux, P. G., Popadin, K., Basset-Seguin, N., Ben Chaabene, R., Santoni, F. A., Andrianova, M. A., Guipponi, M., Garieri, M., Verdan, C., Grosdemange, K., ... Nikolaev, S. I. (2016). Genomic analysis identifies new drivers and progression pathways in skin basal cell carcinoma. Nature genetics, 48(4), 398-406. https://doi.org/10.1038/ng.3525

Biehs, B., Dijkgraaf, G., Piskol, R., Alicke, B., Boumahdi, S., Peale, F., Gould, S. E., \& de 
Sauvage, F. J. (2018). A cell identity switch allows residual BCC to survive Hedgehog pathway inhibition. Nature, 562(7727), 429-433. https://doi.org/10.1038/s41586-018-0596-y Casar Tena, T., Maerz, L. D., Szafranski, K., Groth, M., Blätte, T. J., Donow, C., Matysik, S., Walther, P., Jeggo, P. A., Burkhalter, M. D., \& Philipp, M. (2019). Resting cells rely on the DNA helicase component MCM2 to build cilia. Nucleic acids research, 47(1), 134-151. https://doi.org/10.1093/nar/gky945

Chang, A. L., \& Oro, A. E. (2012). Initial assessment of tumor regrowth after vismodegib in advanced Basal cell carcinoma. Archives of dermatology, 148(11), 1324-1325. https://doi.org/10.1001/archdermatol.2012.2354

Chen, J. H., Geberhiwot, T., Barrett, T. G., Paisey, R., \& Semple, R. K. (2017). Refining genotypephenotype correlation in Alström syndrome through study of primary human fibroblasts. Molecular genetics \& genomic medicine, 5(4), 390-404. https://doi.org/10.1002/mgg3.296

Chiang, A., Jaju, P. D., Batra, P., Rezaee, M., Epstein, E. H., Jr, Tang, J. Y., \& Sarin, K. Y. (2018). Genomic Stability in Syndromic Basal Cell Carcinoma. The Journal of investigative dermatology, 138(5), 1044-1051. https://doi.org/10.1016/j.jid.2017.09.048

Collin, G. B., Cyr, E., Bronson, R., Marshall, J. D., Gifford, E. J., Hicks, W., Murray, S. A., Zheng, Q. Y., Smith, R. S., Nishina, P. M., \& Naggert, J. K. (2005). Alms1-disrupted mice recapitulate human Alström syndrome. Human molecular genetics, 14(16), 2323-2333. https://doi.org/10.1093/hmg/ddi235

Drummond, M. L., Li, M., Tarapore, E., Nguyen, T. T. L., Barouni, B. J., Cruz, S., Tan, K. C., Oro, A. E., \& Atwood, S. X. (2018). Actin polymerization controls cilia-mediated signaling. The Journal of cell biology, 217(9), 3255-3266. https://doi.org/10.1083/jcb.201703196

Eder, A. M., Sui, X., Rosen, D. G., Nolden, L. K., Cheng, K. W., Lahad, J. P., Kango-Singh, M., Lu, K. H., Warneke, C. L., Atkinson, E. N., Bedrosian, I., Keyomarsi, K., Kuo, W. L., Gray, J. W., Yin, J. C., Liu, J., Halder, G., \& Mills, G. B. (2005). Atypical PKCiota contributes to poor prognosis through loss of apical-basal polarity and cyclin E overexpression in ovarian cancer. Proceedings of the National Academy of Sciences of the United States of America, 102(35), 12519-12524. https://doi.org/10.1073/pnas.0505641102

Egeberg, D. L., Lethan, M., Manguso, R., Schneider, L., Awan, A., Jørgensen, T. S., Byskov, A. G., Pedersen, L. B., \& Christensen, S. T. (2012). Primary cilia and aberrant cell signaling in epithelial ovarian cancer. Cilia, 1(1), 15. https://doi.org/10.1186/2046-2530-1-15

Epstein E. H. (2008). Basal cell carcinomas: attack of the hedgehog. Nature reviews. Cancer, 8(10), 743-754. https://doi.org/10.1038/nrc2503

Evans, J. D., Cornford, P. A., Dodson, A., Neoptolemos, J. P., \& Foster, C. S. (2003). Expression 
patterns of protein kinase $\mathrm{C}$ isoenzymes are characteristically modulated in chronic pancreatitis and pancreatic cancer. American journal of clinical pathology, 119(3), 392-402. https://doi.org/10.1309/bkpc9dx98r781b87

Fu, W., Asp, P., Canter, B., \& Dynlacht, B. D. (2014). Primary cilia control hedgehog signaling during muscle differentiation and are deregulated in rhabdomyosarcoma. Proceedings of the National Academy of Sciences, 111(25), $9151 \quad$ LP-9156. https://doi.org/10.1073/pnas.1323265111

Géléoc, G., \& El-Amraoui, A. (2020). Disease mechanisms and gene therapy for Usher syndrome. Hearing research, $107932 . \quad$ Advance online publication. https://doi.org/10.1016/j.heares.2020.107932

Grachtchouk, M., Pero, J., Yang, S. H., Ermilov, A. N., Michael, L. E., Wang, A., Wilbert, D., Patel, R. M., Ferris, J., Diener, J., Allen, M., Lim, S., Syu, L. J., Verhaegen, M., \& Dlugosz, A. A. (2011). Basal cell carcinomas in mice arise from hair follicle stem cells and multiple epithelial progenitor populations. The Journal of clinical investigation, 121(5), 1768-1781. https://doi.org/10.1172/JCl46307

Han, Y. G., Kim, H. J., Dlugosz, A. A., Ellison, D. W., Gilbertson, R. J., \& Alvarez-Buylla, A. (2009). Dual and opposing roles of primary cilia in medulloblastoma development. Nature medicine, 15(9), 1062-1065. https://doi.org/10.1038/nm.2020

Hassounah, N. B., Nagle, R., Saboda, K., Roe, D. J., Dalkin, B. L., \& McDermott, K. M. (2013). Primary cilia are lost in preinvasive and invasive prostate cancer. PloS one, 8(7), e68521. https://doi.org/10.1371/journal.pone.0068521

Hearn T. (2019). ALMS1 and Alström syndrome: a recessive form of metabolic, neurosensory and cardiac deficits. Journal of molecular medicine (Berlin, Germany), 97(1), 1-17. https://doi.org/10.1007/s00109-018-1714-x

Hildebrandt, F., Benzing, T., \& Katsanis, N. (2011). Ciliopathies. The New England journal of medicine, 364(16), 1533-1543. https://doi.org/10.1056/NEJMra1010172

Hirai, T., Niino, Y. S., \& Chida, K. (2003). PKC zeta II, a small molecule of protein kinase C zeta, specifically expressed in the mouse brain. Neuroscience letters, 348(3), 151-154. https://doi.org/10.1016/s0304-3940(03)00780-8

Honda, A., Kita, T., Seshadri, S. V., Misaki, K., Ahmed, Z., Ladbury, J. E., .. Ladher, R. K. (2018). FGFR1-mediated protocadherin-15 loading mediates cargo specificity during intraflagellar transport in inner ear hair-cell kinocilia. Proceedings of the National Academy of Sciences, 115(33), 8388 LP-8393. https://doi.org/10.1073/pnas.1719861115

Huangfu, D., Liu, A., Rakeman, A. S., Murcia, N. S., Niswander, L., \& Anderson, K. V. (2003). 
Hedgehog signalling in the mouse requires intraflagellar transport proteins. Nature, 426(6962), 83-87. https://doi.org/10.1038/nature02061

Jung, B., Padula, D., Burtscher, I., Landerer, C., Lutter, D., Theis, F., Messias, A. C., Geerlof, A., Sattler, M., Kremmer, E., Boldt, K., Ueffing, M., \& Lickert, H. (2016). Pitchfork and Gprasp2 Target Smoothened to the Primary Cilium for Hedgehog Pathway Activation. PloS one, 11(2), e0149477. https://doi.org/10.1371/journal.pone.0149477

Kim, J., Dabiri, S., \& Seeley, E. S. (2011). Primary cilium depletion typifies cutaneous melanoma in situ and malignant melanoma. PloS one, 6(11), e27410. https://doi.org/10.1371/journal.pone.0027410

Kojima, Y., Akimoto, K., Nagashima, Y., Ishiguro, H., Shirai, S., Chishima, T., Ichikawa, Y., Ishikawa, T., Sasaki, T., Kubota, Y., Inayama, Y., Aoki, I., Ohno, S., \& Shimada, H. (2008). The overexpression and altered localization of the atypical protein kinase $\mathrm{C}$ lambda/iota in breast cancer correlates with the pathologic type of these tumors. Human pathology, 39(6), 824-831. https://doi.org/10.1016/j.humpath.2007.11.001

Kuleshov, M. V., Jones, M. R., Rouillard, A. D., Fernandez, N. F., Duan, Q., Wang, Z., Koplev, S., Jenkins, S. L., Jagodnik, K. M., Lachmann, A., McDermott, M. G., Monteiro, C. D., Gundersen, G. W., \& Ma'ayan, A. (2016). Enrichr: a comprehensive gene set enrichment analysis web server 2016 update. Nucleic acids research, 44(W1), W90-W97. https://doi.org/10.1093/nar/gkw377

Kuonen, F., Huskey, N. E., Shankar, G., Jaju, P., Whitson, R. J., Rieger, K. E., Atwood, S. X., Sarin, K. Y., \& Oro, A. E. (2019). Loss of Primary Cilia Drives Switching from Hedgehog to Ras/MAPK Pathway in Resistant Basal Cell Carcinoma. The Journal of investigative dermatology, 139(7), 1439-1448. https://doi.org/10.1016/i.jid.2018.11.035

Lee, C. Y., Robinson, K. J., \& Doe, C. Q. (2006). Lgl, Pins and aPKC regulate neuroblast selfrenewal versus differentiation. Nature, 439(7076), 594-598. https://doi.org/10.1038/nature04299

Lee, J., Yi, S., Won, M., Song, Y. S., Yi, H. S., Park, Y. J., Park, K. C., Kim, J. T., Chang, J. Y., Lee, M. J., Sul, H. J., Choi, J. E., Kim, K. S., Kero, J., Kim, J., \& Shong, M. (2018). Loss-offunction of IFT88 determines metabolic phenotypes in thyroid cancer. Oncogene, 37(32), 4455-4474. https://doi.org/10.1038/s41388-018-0211-6

Liu, H., Kiseleva, A. A., \& Golemis, E. A. (2018). Ciliary signalling in cancer. Nature reviews. Cancer, 18(8), 511-524. https://doi.org/10.1038/s41568-018-0023-6

Marszalek, J. R., Ruiz-Lozano, P., Roberts, E., Chien, K. R., \& Goldstein, L. S. (1999). Situs inversus and embryonic ciliary morphogenesis defects in mouse mutants lacking the KIF3A 
subunit of kinesin-II. Proceedings of the National Academy of Sciences of the United States of America, 96(9), 5043-5048. https://doi.org/10.1073/pnas.96.9.5043

Menzl, I., Lebeau, L., Pandey, R., Hassounah, N. B., Li, F. W., Nagle, R., Weihs, K., \& McDermott, K. M. (2014). Loss of primary cilia occurs early in breast cancer development. Cilia, 3, 7. https://doi.org/10.1186/2046-2530-3-7

Neve, A., Migliavacca, J., Capdeville, C., Schönholzer, M. T., Gries, A., Ma, M., Santhana Kumar, K., Grotzer, M., \& Baumgartner, M. (2019). Crosstalk between SHH and FGFR Signaling Pathways Controls Tissue Invasion in Medulloblastoma. Cancers, 11(12), 1985. https://doi.org/10.3390/cancers11121985

Nguyen, T.T.L., Tarapore, E., Atwood, S.X. (2019). Common Skin Diseases - Skin Cancer. In Imaging technologies and transdermal delivery in skin disorders. Wiley. ISBN: 978-3-52734460-4. https://doi.org/10.1002/9783527814633.ch5

Pak, E., \& Segal, R. A. (2016). Hedgehog Signal Transduction: Key Players, Oncogenic Drivers, and Cancer Therapy. Developmental cell, 38(4), 333-344. https://doi.org/10.1016/i.devcel.2016.07.026

Regala, R. P., Weems, C., Jamieson, L., Khoor, A., Edell, E. S., Lohse, C. M., \& Fields, A. P. (2005). Atypical protein kinase $C$ iota is an oncogene in human non-small cell lung cancer. Cancer research, 65(19), 8905-8911. https://doi.org/10.1158/0008-5472.CAN-05-2372

Roeseler, D. A., Sachdev, S., Buckley, D. M., Joshi, T., Wu, D. K., Xu, D., Hannink, M., \& Waters, S. T. (2012). Elongation factor 1 alpha1 and genes associated with Usher syndromes are downstream targets of GBX2. PloS one, 7(11), e47366. https://doi.org/10.1371/journal.pone.0047366

Roignot, J., Peng, X., \& Mostov, K. (2013). Polarity in mammalian epithelial morphogenesis. Cold Spring Harbor perspectives in biology, 5(2), a013789. https://doi.org/10.1101/cshperspect.a013789

Sánchez-Danés, A., Larsimont, J. C., Liagre, M., Muñoz-Couselo, E., Lapouge, G., Brisebarre, A., Dubois, C., Suppa, M., Sukumaran, V., Del Marmol, V., Tabernero, J., \& Blanpain, C. (2018). A slow-cycling LGR5 tumour population mediates basal cell carcinoma relapse after therapy. Nature, 562(7727), 434-438. https://doi.org/10.1038/s41586-018-0603-3

Satir, P., Pedersen, L. B., \& Christensen, S. T. (2010). The primary cilium at a glance. Journal of cell science, 123(Pt 4), 499-503. https://doi.org/10.1242/jcs.050377

Schraml, P., Frew, I. J., Thoma, C. R., Boysen, G., Struckmann, K., Krek, W., \& Moch, H. (2009). Sporadic clear cell renal cell carcinoma but not the papillary type is characterized by severely reduced frequency of primary cilia. Modern pathology : an official journal of the United States 
and Canadian Academy of Pathology, Inc, 22(1), 31-36. https://doi.org/10.1038/modpathol.2008.132

Seeley, E. S., Carrière, C., Goetze, T., Longnecker, D. S., \& Korc, M. (2009). Pancreatic cancer and precursor pancreatic intraepithelial neoplasia lesions are devoid of primary cilia. Cancer research, 69(2), 422-430. https://doi.org/10.1158/0008-5472.CAN-08-1290

Sekulic, A., Migden, M. R., Oro, A. E., Dirix, L., Lewis, K. D., Hainsworth, J. D., Solomon, J. A., Yoo, S., Arron, S. T., Friedlander, P. A., Marmur, E., Rudin, C. M., Chang, A. L., Low, J. A., Mackey, H. M., Yauch, R. L., Graham, R. A., Reddy, J. C., \& Hauschild, A. (2012). Efficacy and safety of vismodegib in advanced basal-cell carcinoma. The New England journal of medicine, 366(23), 2171-2179. https://doi.org/10.1056/NEJMoa1113713

Sharpe, H. J., Pau, G., Dijkgraaf, G. J., Basset-Seguin, N., Modrusan, Z., Januario, T., Tsui, V., Durham, A. B., Dlugosz, A. A., Haverty, P. M., Bourgon, R., Tang, J. Y., Sarin, K. Y., Dirix, L., Fisher, D. C., Rudin, C. M., Sofen, H., Migden, M. R., Yauch, R. L., \& de Sauvage, F. J. (2015). Genomic analysis of smoothened inhibitor resistance in basal cell carcinoma. Cancer cell, 27(3), 327-341. https://doi.org/10.1016/j.ccell.2015.02.001

Slenter, D. N., Kutmon, M., Hanspers, K., Riutta, A., Windsor, J., Nunes, N., Mélius, J., Cirillo, E., Coort, S. L., Digles, D., Ehrhart, F., Giesbertz, P., Kalafati, M., Martens, M., Miller, R., Nishida, K., Rieswijk, L., Waagmeester, A., Eijssen, L., Evelo, C. T., ... Willighagen, E. L. (2018). WikiPathways: a multifaceted pathway database bridging metabolomics to other omics research. Nucleic acids research, 46(D1), D661-D667. https://doi.org/10.1093/nar/gkx1064

So, P. L., Langston, A. W., Daniallinia, N., Hebert, J. L., Fujimoto, M. A., Khaimskiy, Y., Aszterbaum, M., \& Epstein, E. H., Jr (2006). Long-term establishment, characterization and manipulation of cell lines from mouse basal cell carcinoma tumors. Experimental dermatology, 15(9), 742-750. https://doi.org/10.1111/j.1600-0625.2006.00465.x

Szabó, N.-E., Zhao, T., Zhou, X., \& Alvarez-Bolado, G. (2009). The Role of Sonic Hedgehog of Neural Origin in Thalamic Differentiation in the Mouse. The Journal of Neuroscience, 29(8), 2453 LP-2466. https://doi.org/10.1523/JNEUROSCI.4524-08.2009

Takeda, S., Yonekawa, Y., Tanaka, Y., Okada, Y., Nonaka, S., \& Hirokawa, N. (1999). Left-right asymmetry and kinesin superfamily protein KIF3A: new insights in determination of laterality and mesoderm induction by kif3A-/- mice analysis. The Journal of cell biology, 145(4), 825836. https://doi.org/10.1083/jcb.145.4.825

Tan, S. T., Ghaznawie, M., Heenan, P. J., \& Dosan, R. (2018). Basal Cell Carcinoma Arises from Interfollicular Layer of Epidermis. Journal of oncology, 2018, 3098940. 


\section{https://doi.org/10.1155/2018/3098940}

Tsokas, P., Hsieh, C., Yao, Y., Lesburguères, E., Wallace, E., Tcherepanov, A., Jothianandan, D., Hartley, B. R., Pan, L., Rivard, B., Farese, R. V., Sajan, M. P., Bergold, P. J., Hernández, A. I., Cottrell, J. E., Shouval, H. Z., Fenton, A. A., \& Sacktor, T. C. (2016). Compensation for $\mathrm{PKM} \zeta$ in long-term potentiation and spatial long-term memory in mutant mice. eLife, 5, e14846. https://doi.org/10.7554/eLife.14846

van Dam, T. J., Wheway, G., Slaats, G. G., SYSCILIA Study Group, Huynen, M. A., \& Giles, R. H. (2013). The SYSCILIA gold standard (SCGSv1) of known ciliary components and its applications within a systems biology consortium. Cilia, 2(1), 7. https://doi.org/10.1186/20462530-2-7

Varjosalo, M., \& Taipale, J. (2008). Hedgehog: functions and mechanisms. Genes \& development, 22(18), 2454-2472. https://doi.org/10.1101/gad.1693608

Wang, G. Y., So, P. L., Wang, L., Libove, E., Wang, J., \& Epstein, E. H., Jr (2011). Establishment of murine basal cell carcinoma allografts: a potential model for preclinical drug testing and for molecular analysis. The Journal of investigative dermatology, 131(11), 2298-2305. https://doi.org/10.1038/jid.2011.204

Wheway, G., Nazlamova, L., \& Hancock, J. T. (2018). Signaling through the Primary Cilium. Frontiers in cell and developmental biology, 6, 8. https://doi.org/10.3389/fcell.2018.00008

Williams, E. H., Pappano, W. N., Saunders, A. M., Kim, M.-S., Leahy, D. J., \& Beachy, P. A. (2010). Dally-like core protein and its mammalian homologues mediate stimulatory and inhibitory effects on Hedgehog signal response. Proceedings of the National Academy of Sciences, 107(13), 5869 LP-5874. https://doi.org/10.1073/pnas.1001777107

Wong, S. Y., Seol, A. D., So, P. L., Ermilov, A. N., Bichakjian, C. K., Epstein, E. H., Jr, Dlugosz, A. A., \& Reiter, J. F. (2009). Primary cilia can both mediate and suppress Hedgehog pathwaydependent tumorigenesis. Nature medicine, 15(9), 1055-1061. https://doi.org/10.1038/nm.2011

Wu, F., Zhang, Y., Sun, B., McMahon, A. P., \& Wang, Y. (2017). Hedgehog Signaling: From Basic Biology to Cancer Therapy. Cell chemical biology, 24(3), 252-280. https://doi.org/10.1016/j.chembiol.2017.02.010

Yang, Y. L., Chu, J. Y., Luo, M. L., Wu, Y. P., Zhang, Y., Feng, Y. B., Shi, Z. Z., Xu, X., Han, Y. L., Cai, Y., Dong, J. T., Zhan, Q. M., Wu, M., \& Wang, M. R. (2008). Amplification of PRKCI, located in $3 q 26$, is associated with lymph node metastasis in esophageal squamous cell carcinoma. Genes, chromosomes \& cancer, 47(2), 127-136. https://doi.org/10.1002/gcc.20514 
Yuan, K., Frolova, N., Xie, Y., Wang, D., Cook, L., Kwon, Y. J., Steg, A. D., Serra, R., \& Frost, A. R. (2010). Primary cilia are decreased in breast cancer: analysis of a collection of human breast cancer cell lines and tissues. The journal of histochemistry and cytochemistry : official journal of the Histochemistry Society, 58(10), 857-870. https://doi.org/10.1369/jhc.2010.955856

Yuan, Z., Goetz, J. A., Singh, S., Ogden, S. K., Petty, W. J., Black, C. C., Memoli, V. A., Dmitrovsky, E., \& Robbins, D. J. (2007). Frequent requirement of hedgehog signaling in nonsmall cell lung carcinoma. Oncogene, 26(7), 1046-1055. https://doi.org/10.1038/sj.onc.1209860

Zhang, Y., Bulkley, D. P., Xin, Y., Roberts, K. J., Asarnow, D. E., Sharma, A., Myers, B. R., Cho, W., Cheng, Y., \& Beachy, P. A. (2018). Structural Basis for Cholesterol Transport-like Activity of the Hedgehog Receptor Patched. Cell, 175(5), 1352-1364.e14. https://doi.org/10.1016/j.cell.2018.10.026

Zheng, X., Mann, R. K., Sever, N., \& Beachy, P. A. (2010). Genetic and biochemical definition of the Hedgehog receptor. Genes \& development, 24(1), 57-71. https://doi.org/10.1101/gad.1870310

Zingg, D., Debbache, J., Peña-Hernández, R., Antunes, A. T., Schaefer, S. M., Cheng, P. F., Zimmerli, D., Haeusel, J., Calçada, R. R., Tuncer, E., Zhang, Y., Bossart, R., Wong, K. K., Basler, K., Dummer, R., Santoro, R., Levesque, M. P., \& Sommer, L. (2018). EZH2-Mediated Primary Cilium Deconstruction Drives Metastatic Melanoma Formation. Cancer cell, 34(1), 69-84.e14. https://doi.org/10.1016/j.ccell.2018.06.001 
A
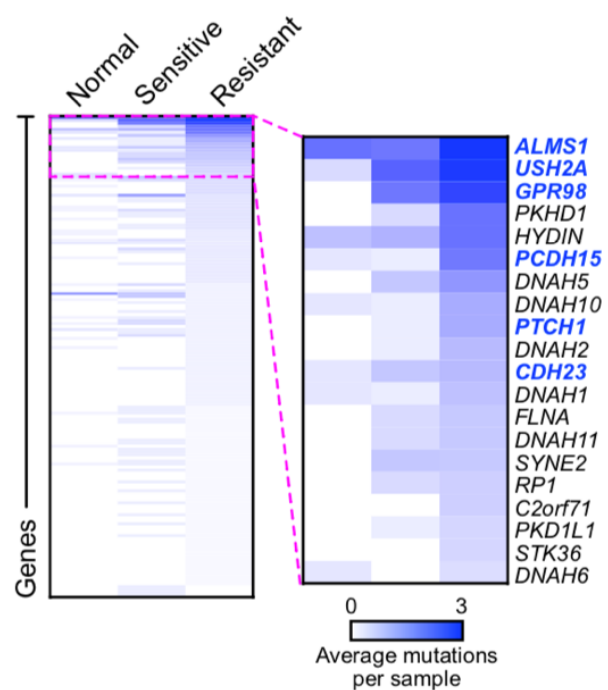

B

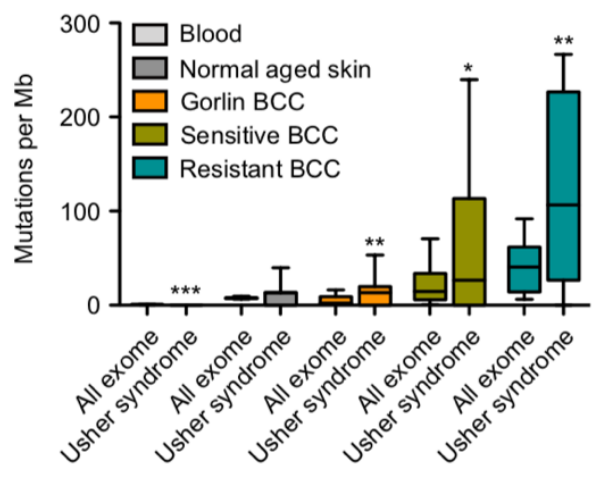

C

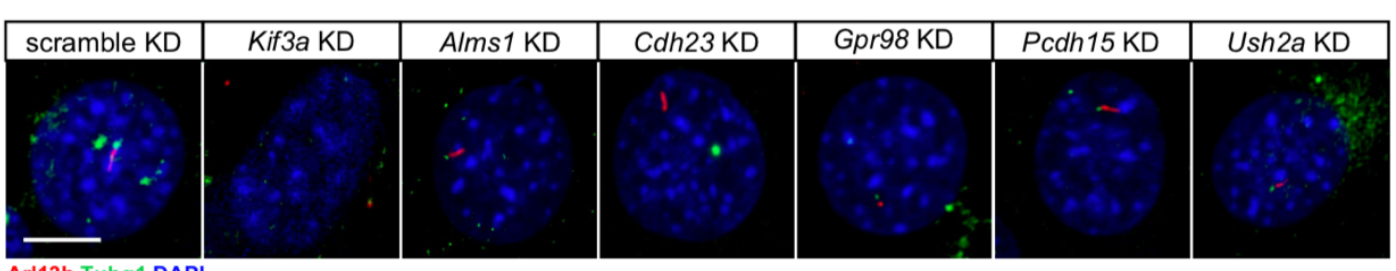
Arl13b Tubg1 DAPI

D

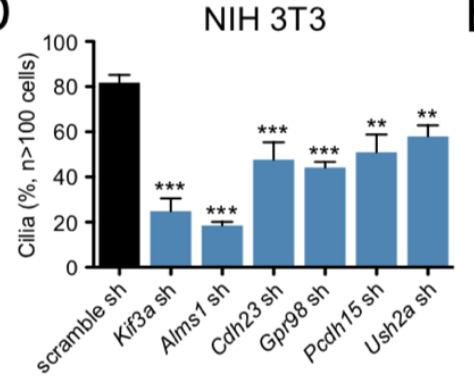

E

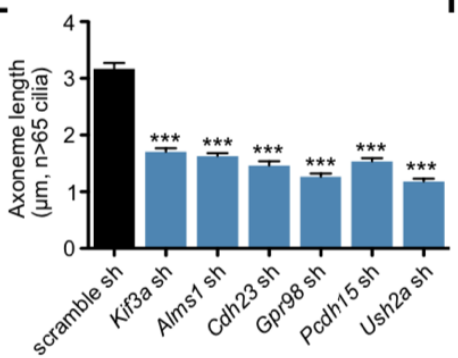

F

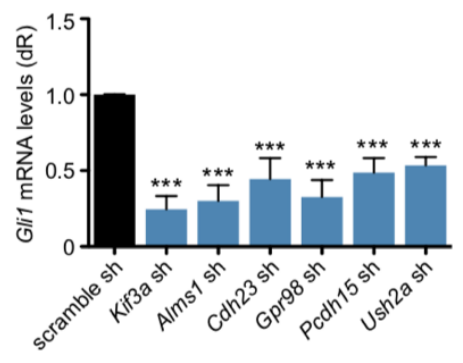

G

\begin{tabular}{|c|c|c|c|c|c|c|}
\hline scramble KD & Kif3a KD & Alms1 KD & Cdh23 KD & Gpr98 KD & Pcdh15 KD & Ush2a KD \\
\hline - & $\because$ & $+\therefore$ & $\cdot$ & 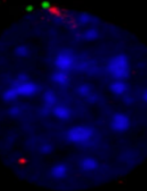 & $\frac{3}{5}$ & 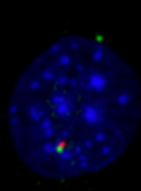 \\
\hline
\end{tabular}

Arl13b Tubg1 DAPI
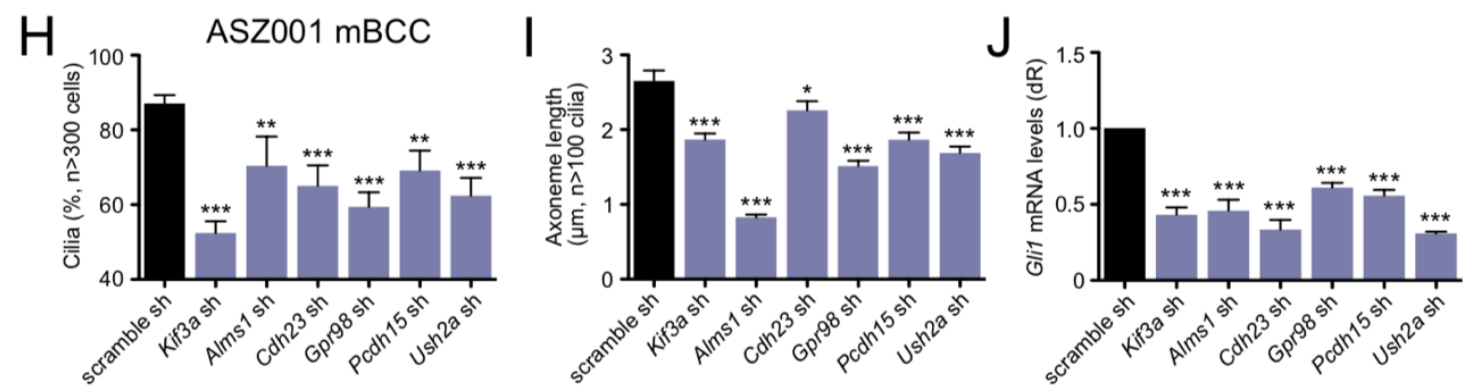
Figure 1. Alström and Usher syndrome genes are highly mutated in advanced BCCs and are necessary to maintain primary ciliogenesis and $\mathrm{HH}$ signaling. (A) Heatmap depicting average mutations per sample of 161 mutated ciliary genes from exome sequencing of normal $(n=7)$, SMO inhibitor-sensitive ( $n=4)$, and SMO inhibitor-resistant $(n=11)$ advanced BCCs (Atwood et al. 2015). The top 20 most mutated ciliary genes depicted on the right. (B) Box and whisker plot comparing mutations per megabase $(\mathrm{Mb})$ of Usher syndrome genes versus background in blood ( $n=25)$, normal aged skin $(n=7)$, Gorlin syndrome BCCs $(n=21)$, SMO inhibitor-sensitive BCCs ( $n=13)$, and SMO inhibitor-resistant BCCs ( $n=11)$ (Atwood et al. 2015; Chiang et al. 2018). (C-F) Representative immunofluorescent images (C), percentage (\%) of ciliated cells (D), average axoneme length (E), and Gli1 mRNA levels (F) of shRNA (sh)-mediated knockdown (KD) of scramble control, Kif3a, Alms1, Cdh23, Grp98, Pcdh15, or Ush2a in NIH3T3 cells and stained for Arl13b, $\mathrm{y}$-tubulin (Tubg1), and DAPI. $\mathrm{n} \geq 3$. dR, delta reporter signal normalized to passive reference dye. Scale bar $10 \mu \mathrm{m}$. (G-J) Representative immunofluorescent images (G), percentage of ciliated cells $(\mathbf{H})$, average axoneme length $(\mathbf{I})$, and Gli1 mRNA levels $(\mathbf{J})$ of shRNAmediated KD of ASZ001 cells. Scale bar $10 \mu \mathrm{m}$. Error bars represent SEM; significance was determined by unpaired two-tailed $t$ test $\left({ }^{*}, p<0.05 ;{ }^{* *}, p<0.01 ;{ }^{* * *}, p<0.001\right)$. 


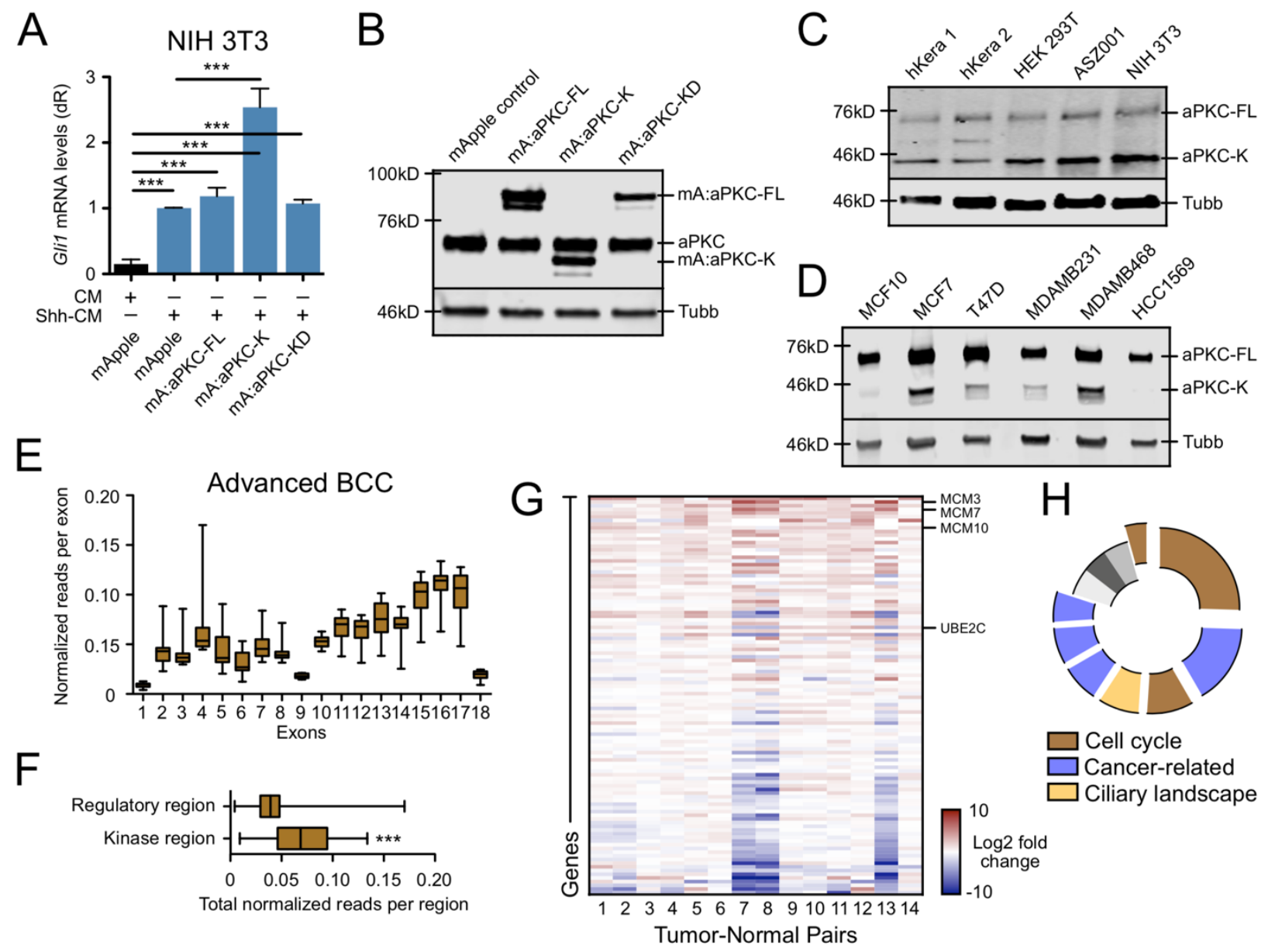

Figure 2. Constitutively active aPKC isoform promotes $\mathrm{HH}$ signaling and is expressed in various normal and cancerous backgrounds. (A) Gli1 mRNA levels of NIH3T3 cells overexpressing mApple control, mApple:aPKC-FL, mApple:aPKC-K, or mApple:aPKC-KD constructs in the presence of conditioned media (CM) or Shh-CM. $n \geq 5$. dR, delta reporter signal normalized to passive reference dye. mA, mApple. FL, full-length. $K$, kinase. KD, kinase dead. $\mathrm{CM}$, condition media. (B) Western blots of NIH3T3 cells overexpressing the indicated aPKC constructs. Signal of top blot from C-terminal aPKC antibody. Signal of bottom blot from $\beta$-tubulin (Tubb) antibody. kD, kilodalton. (C-D) Western blots of the indicated cell lines with signal from a C-terminal aPKC antibody (top) or Tubb antibody (bottom). hKera, primary human keratinocyte. (E) Quantification of normalized reads per exon of the PRKCl gene from 14 advanced human BCC tumors (Atwood et al. 2015). Data normalized to read length. (F) Quantification of total normalized reads per region of the $P R K C I$ gene from $(E)$. Regulatory region covers exon 1-8 and kinase region covers exon 9-18. (G) Heatmap of aPKC signature genes in 14 tumor-normal pairs of advanced BCCs (Atwood et al. 2015). (H) Wikipathways analysis of upregulated aPKC-specific 
bioRxiv preprint doi: https://doi.org/10.1101/2020.06.08.137216; this version posted June 9, 2020. The copyright holder for this preprint (which was not certified by peer review) is the author/funder. All rights reserved. No reuse allowed without permission.

genes with their significant terms. Error bars represent SEM; significance was determined by unpaired two-tailed $t$ test $\left({ }^{*}, \mathrm{p}<0.05 ;{ }^{* *}, \mathrm{p}<0.01 ;{ }^{* * *}, \mathrm{p}<0.001\right)$. 


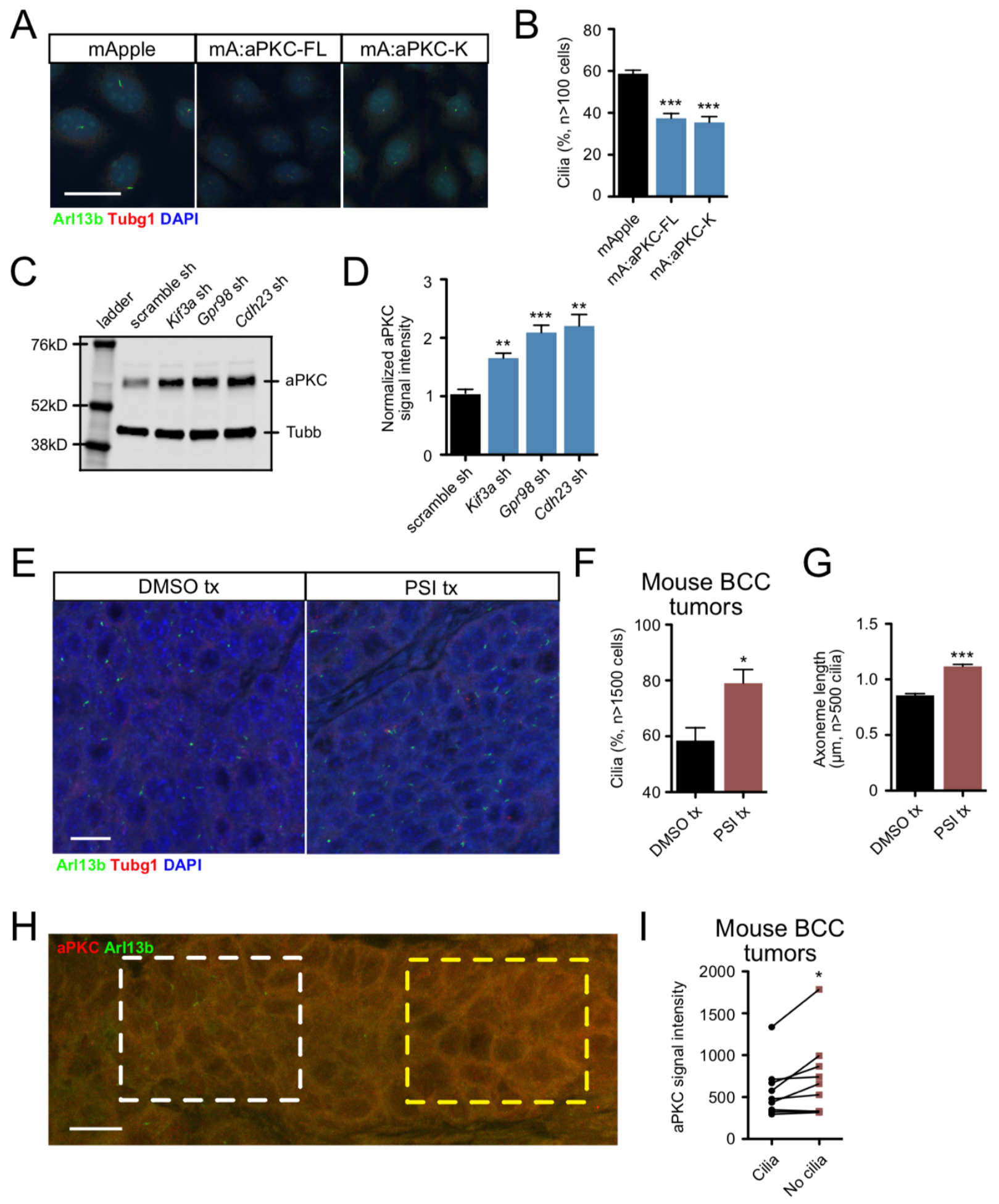

Figure 3. aPKC and primary cilia mutually inhibit each other. (A) Immunofluorescence of ASZ001 cells expressing mApple, mApple:aPKC-FL, or mApple:aPKC-K constructs and stained with Arl13b for cilia shafts, $y$-tubulin (Tubg1) for basal bodies, and DAPI for nuclei. Scale bar, 30 um. mA, mApple. FL, full-length. K, kinase. (B) Percentage of ciliated NIH3T3 cells expressing 
mApple, mApple-aPKC-FL, or mApple-aPKC-K constructs. \%, percentage. (C) Western blot of NIH3T3 cell lysates infected with lentivirus containing control, Kif3a, Grp98, or Cdh23 shRNAs and probed for aPKC and $\beta$-tubulin (Tubb). sh, shRNA. kD, kilodalton. (D) Normalized intensity of aPKC:Tubb from (C). $n=4$. (E) Immunofluorescence of DMSO-treated or PSI-treated allograft BCCs generated from Ptch1+/-; Trp53 floxflox; Krt14-Cre-ER2 mice and stained for the indicated antibodies. Scale bar, $10 \mu \mathrm{m}$. tx, treatment. (F-G) Quantification of ciliated cells (F) and axoneme length (G) from (E). (H) Immunofluorescence of adjacent regions in an allograft BCC tumor sample stained for the indicated antibodies. Scale bar, $10 \mu \mathrm{m}$. White dotted square outlines a ciliated section. Yellow dotted square outlines a section without cilia. (I) aPKC immunofluorescence intensity in ciliated versus non-ciliated regions within the same murine allograft BCC tumors, $n=9$. Error bars represent SEM; significance was determined by unpaired two-tailed $t$ test (B, D, F-G) or paired two-tailed $t$ test $(\mathrm{I})\left({ }^{*}, \mathrm{p}<0.05 ;{ }^{* *}, \mathrm{p}<0.01 ;{ }^{* * *}, \mathrm{p}<0.001\right)$. 

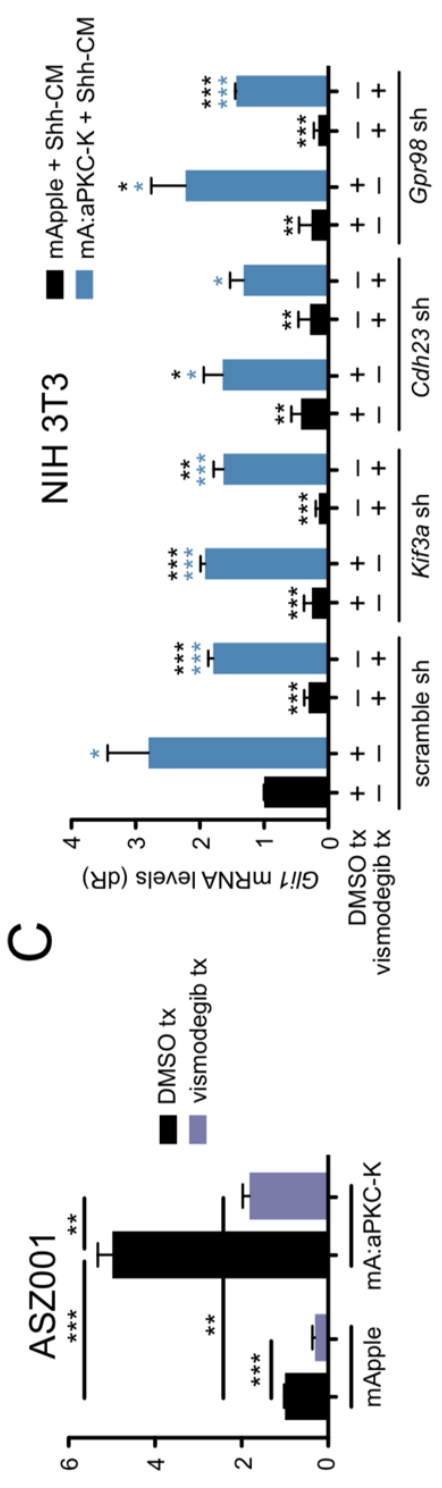

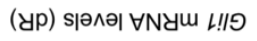

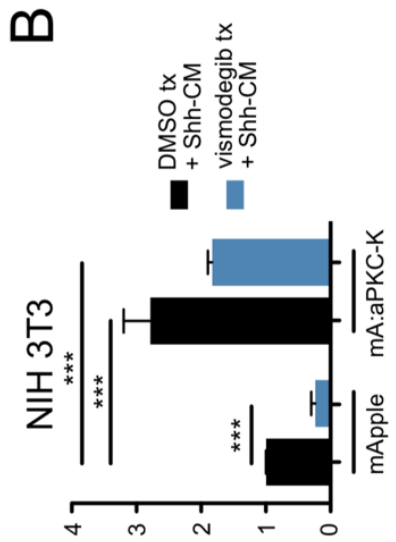

(ур) s|әлә| $\forall N y$ u L!IO

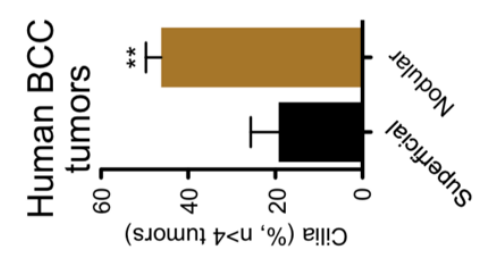

ш

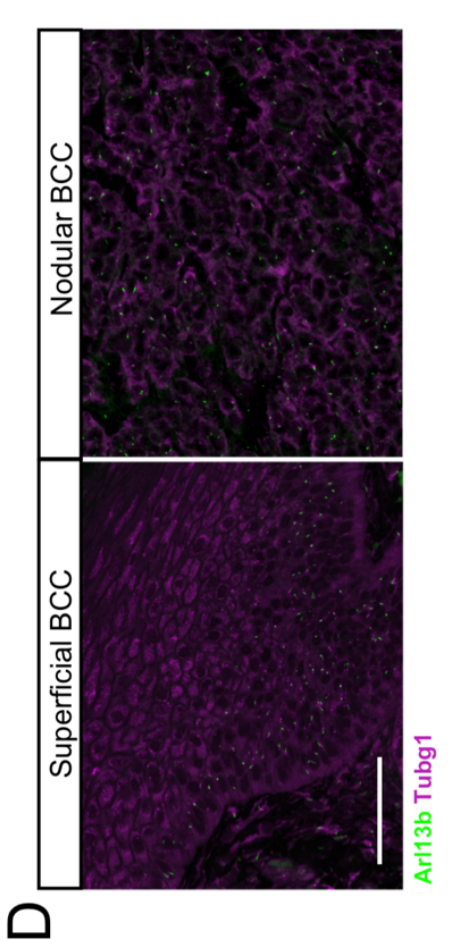

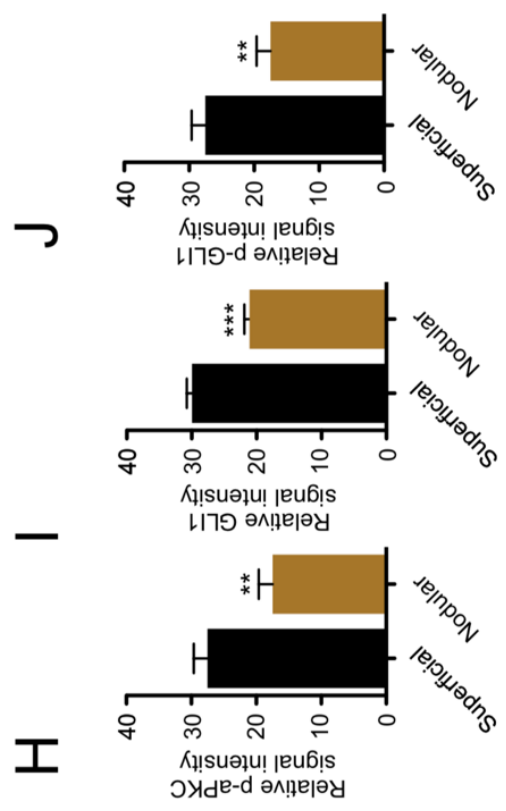

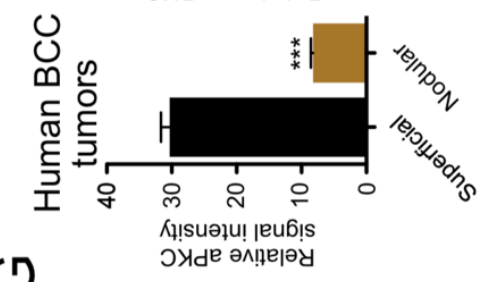

(1)

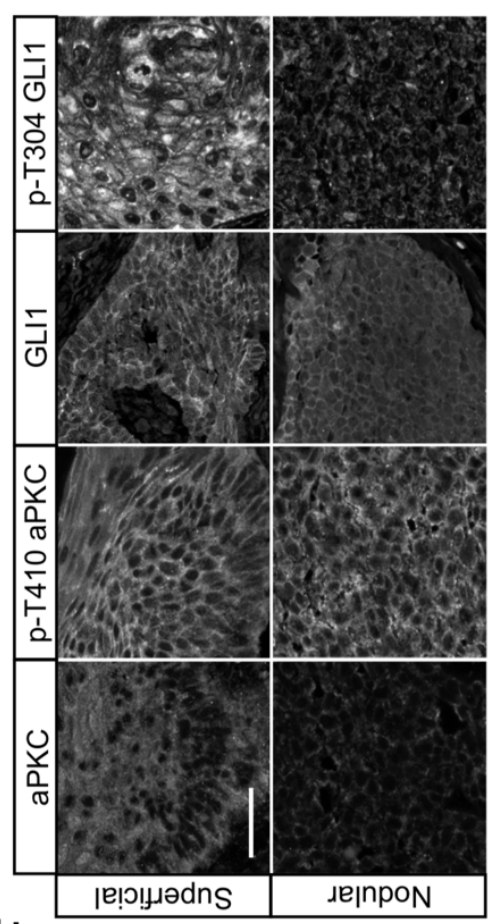

レ 
Figure 4. aPKC confers vismodegib resistance regardless of ciliation and is differentially expressed in human tumors. (A-B) Gli1 mRNA levels of NIH3T3 cells (A) or ASZ001 cells (B) expressing mApple or mApple-aPKC-K constructs and treated with DMSO or 100nM vismodegib. $\mathrm{n} \geq 3$. $\mathrm{dR}$, delta reporter signal normalized to passive reference dye. $\mathrm{mA}, \mathrm{mApple.} \mathrm{K}$, kinase. CM, conditioned media. tx, treatment. (C) Gli1 mRNA levels of NIH 3T3 cells expressing mApple or mApple-aPKC-K containing the indicated shRNAs (sh) and treated with DMSO or 100nM vismodegib. $n \geq 3$. Black stars are $p$ values compared to scramble sh DMSO treatment. Blue stars are $p$ values compared to internal experimental mApple controls. (D) Representative images of superficial or nodular human BCCs stained with Arl13b for cilia shafts and $y$-tubulin (Tubg1) for basal bodies. Scale bar, $50 \mu \mathrm{m}$. (E) Quantification of ciliated cells from superficial or nodular human BCC tumors. $\mathrm{n} \geq 4$ tumors. (F) Representative images of superficial or nodular human BCCs stained with the indicated antibodies. Scale bar, $50 \mu \mathrm{m}$. (G-J) Quantification of tumor immunofluorescence for total aPKC $(\mathrm{G})$, phosphorylated aPKC at T410 (H), total GLI1 (I), and phosphorylated GLI1 at T304 (J). n $\geq 4$ tumors. Error bars represent SEM; significance was determined by unpaired two-tailed $t$ test $\left({ }^{*}, p<0.05 ;{ }^{* *}, p<0.01 ;{ }^{* * *}, p<0.001\right)$. 

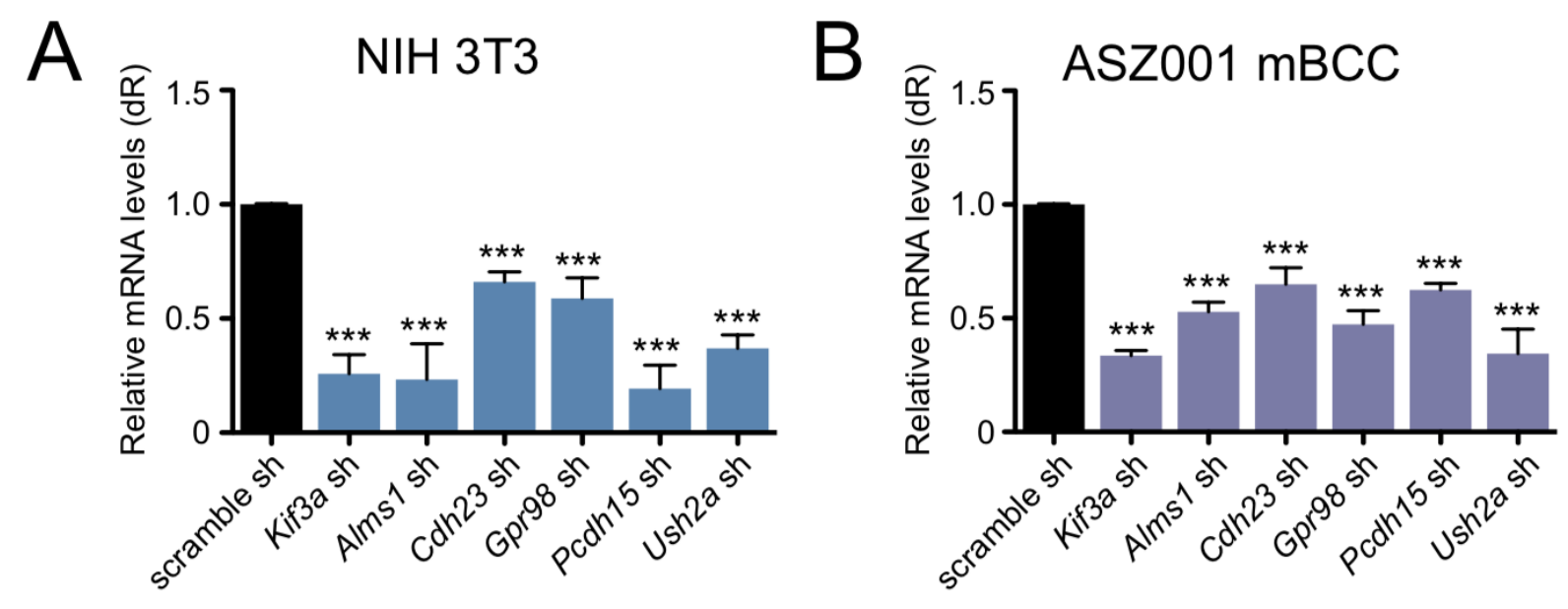

Supplementary Figure 1. Lentiviral knockdown of Alström and Usher syndrome genes. (AB) shRNA-mediated knockdown of the indicated genes in NIH3T3 cells (A) or ASZ001 cells (B). $n \geq 3$. $d R$, delta reporter signal normalized to passive reference dye. sh, shRNA. Error bars represent SEM; significance was determined by unpaired two-tailed $t$ test $\left({ }^{*}, p<0.05 ;{ }^{* *}, p<0.01\right.$; $\left.{ }^{* * *}, p<0.001\right)$. 